\title{
Arbor
}

\section{El desafío de la logística}

\author{
Marín Bello Crespo
}

Arbor CLXV, 651 (Marzo 2000), 489-508 pp.

"La Historia sabe de muchos más ejércitos arruinados por la necesidad y el desorden que por los esfuerzos de sus enemigos».

Richelieu

\section{Introducción}

Posiblemente, no se puede encontrar a nadie más capacitado para explicar de una forma sencilla la esencia de la logística que un ama de casa normal y corriente. En su ajetreado quehacer diario, el ama de casa, para resolver los variados problemas que plantea el vivir de cada día, tiene que planear, programar y realizar ese conjunto de actividades que hemos dado en llamar logística, y que a nivel doméstico reproducen fielmente, de una manera no siempre elemental, el entramado sistemático y complejo en que se ha convertido hoy en día este «arte sin gloria», cuya importancia ha sido siempre decisiva para ganar las guerras.

Cualquier gestor logístico, al igual que cualquier ama de casa, debe enfrentarse desde el inicio de su trabajo con una serie de problemas fundamentales que se derivan, realmente, de una cuestión clave: cubrir las necesidades de la organización, o de la familia, partiendo del hecho cierto de que, con los recursos de que dispone, no puede atender a todas las que serían deseables. ¿Cómo hacer frente a todas necesidades de un hogar, o de un Ejército, con los limitados recursos de un salario, o de un presupuesto?. En otras palabras, ¿qué es lo imprescindible, lo necesario y lo accesorio? Es la eterna cuestión de saber distinguir entre POSIBILIDAD y NECESIDAD, cuya única solución consiste en identificar, determinar y clasificar los recursos siguiendo un orden de prioridades. 
La determinación de prioridades es, pues, el concepto que está en el origen de toda planificación logística, y se aplica a todos los niveles; allí donde existen unas necesidades que satisfacer, desde la célula que podríamos considerar elemental -el hogar- hasta la organización más compleja que podamos imaginar, los problemas prácticos para resolver las cuestiones logísticas siempre serán los mismos, y tendrán como denominador común el desequilibrio constante entre el volumen de necesidades a satisfacer y las posibilidades de atenderlas.

Llegados a este punto, cabe preguntarse qué es lo que entendemos por Logística, cuál ha sido su evolución a través de los tiempos, qué estructura o estructuras ha ido adoptando para adaptarse a las épocas y a las circunstancias y en qué situación se halla, en el Ejército español, en estos momentos.

Esa es la finalidad de este trabajo, que no pretende profundizar excesivamente ni entretenerse en los detalles, sino intentar ofrecer a los lectores un panorama que de algún modo les acerque a la teoría y a la realidad de la Logística, les muestre la importancia decisiva que tuvo en el pasado y que tiene en el presente, y les plantee los principales problemas a los que debe hacer frente.

\title{
El hombre, fundamento de la actividad logística
}

\author{
«En los ejércitos hay dos cosas muy distintas, una que se ve y \\ otra que no se ve, que es la más importante, de la cual prescinden \\ por completo los profanos. Componen la primera los hombres \\ formados en batallones, escuadrones y baterías, con su vestuario, \\ equipo y armamento; la segunda, los elementos para alimentar, \\ vestir y municionar al soldado mientras se halle en estado de pelear, \\ para cuidarle y asistirle cuando cae herido o enfermo y para \\ reemplazar las bajas que sobrevengan en las filas, a fin de que la \\ campaña no termine por falta del número necesario de \\ combatientes" \\ General O’Ryan y Vázquez
}

La Doctrina para el Empleo de la Fuerza Terrestre define la Logística como la «rama del Arte Militar que planifica y ejecuta las actividades necesarias para constituir y sostener las fuerzas, en los lugares adecuados y en los momentos oportunos, en orden al cumplimiento de su misión». Esta definición, en su brevedad conceptual, encierra un vastísimo campo de acciones de todo tipo, programadas y realizadas 
a todos los niveles, que afectan a todos los recursos y energías, empezando por los más fundamentales, que son los recursos humanos.

En efecto, «constituir fuerzas» es, ante todo, dotarlas de personal. El factor primario de cualquier fuerza militar son los hombres que la componen (hoy día, los hombres y las mujeres), en cualquier nivel de mando y actividad. Vamos a ver qué procedimientos han sido empleados, a lo largo de los tiempos, para satisfacer esta necesidad.

Desde los albores de la Historia, con la aparición de las primeras ciudades sumerias, ha existido lo que se ha dado en llamar la «casta de los guerreros», expresión del poder del príncipe reinante y elemento de coerción hacia cualquier potencial oponente, interior o exterior. Es claro que, en sus orígenes, el sustento militar de cualquier líder surge de su clan familiar, del núcleo de sus afines, dado que está en el principio del poder que nace del predominio de un clan, de una familia, sobre las demás.

El entramado de relaciones que surgen entre el poderoso y los que le rodean incluye, como factor de capital importancia, el apoyo armado de éstos a cambio del favor de aquél frente a otros competidores económicos o sociales. Un apoyo prestado en principio a título personal y, luego, ampliado al conjunto del clan y de los sirvientes $\mathrm{y}$ esclavos.

La constitución de Estados, primero en el ámbito de la ciudad y luego, por la expansión y la conquista, en el ámbito de espacios territoriales más amplios, lleva consigo un aumento de la necesidad de hombres de armas y, lo que es más, de la especialización de éstos. El paso a la Edad del Bronce, y de ésta a la del Hierro, suponen cambios tecnológicos trascendentales que llevan consigo cambios en la estrategia y en la logística de las organizaciones militares. Se necesitan más hombres, más medios de transporte, más especialistas en las nuevas técnicas de fabricación de armas y pertrechos. La obtención de combatientes y, en general, de todo el personal necesario para la organización, son factores claves del poder militar.

En la antigua Grecia, democracia y sentido nacional son el embrión de los primeros ejércitos organizados. En la democrática Atenas, en Beocia, en Argos, en la militarizada Esparta, la dureza de la instrucción en el orden de batalla, la existencia de magníficos generales, la organización avanzada de sus tropas, y el sentido cívico y patriótico de sus soldados son las claves de sus resonantes éxitos frente a la masa desorganizada de los persas. Pero esa organización era también el resultado de un conjunto de actividades logísticas que eran capaces de constituir y mantener ejércitos aguerridos, disciplinados y bien ar- 
mados. Es famoso el dicho espartano de «las murallas de Esparta son los pechos de sus ciudadanos», pero con sólo esos valientes pechos Esparta no habría conseguido mantenerse largo tiempo como potencia hegemónica en Grecia; en realidad, ese temible poder militar nacía de una filosofía nacional que hacía soldados'a los espartanos desde su nacimiento.

A la avanzada estructura social, que opone ejércitos motivados y organizados frente a masas a menudo famélicas y arrastradas a la guerra contra su voluntad y sin ninguna motivación ni preparación, está el origen y la clave de los éxitos no sólo en las Guerras Médicas, libradas al fín y al cabo en suelo y en aguas griegas, sino en las expediciones de Alejandro en Asia y la subsiguiente creación de su vasto imperio helenístico. De ahí un primer principio perfectamente aplicable por cualquier gestor: un combatiente bien entrenado y motivado es infinitamente superior a otro reclutado a la fuerza.

Roma dio, ya desde sus orígenes, gran importancia a la generación y regeneración de recursos humanos. Sólo una portentosa organización pudo oponer a Aníbal cuatro ejércitos de 40/50.000 hombres, que fueron derrotados sucesivamente en Tesino, Trebia, Trasimeno y Cannas. Al final, tras dieciséis años de lucha en territorio italiano, el genio cartaginés hubo de retirarse, incapaz de vencer a una nación cuyos jefes militares no eran ni siquiera elegidos en función de su pericia militar, sino de intereses políticos de partido.

No cabe ninguna expansión sin superioridad política, económica y social sobre la población del territorio a ocupar, que se traducen en una mejor organización logística y, por tanto, en una superioridad militar. Esa es la clave de la constitución y el desarrollo de los imperios que se han sucedido a través de los siglos, así como su hundimiento ha sido el efecto de una pérdida de la capacidad para mantener lo conquistado, muchas veces debida al agotamiento demográfico y de recursos producido por la misma expansión. En todo caso, hasta la Revolución Francesa, las condiciones de las campañas no hicieron posible, en la mayoría de los casos, la constitución de grandes ejércitos. La «nacionalización» de la guerra trajo consigo los ejércitos de centenares de miles, de millones de hombres; los ejércitos profesionales de la Edad Moderna dieron paso a grandes masas, a grandes guerras y a grandes pérdidas.

Esta situación -efectivos numerosos, gastos de defensa importantes e industria militar autosuficiente en lo posible- ha caracterizado toda la postguerra prácticamente hasta la caída del muro de Berlín. 
El final de la Guerra Fría y la consiguiente presión social para disminuir efectivos y gastos por un lado, y la creciente necesidad de personal especializado para atender a materiales y tareas cada vez más complejos por otro, han impulsado con fuerza un nuevo ciclo de profesionalización, que se extiende por el mundo desarrollado y que acabará por alcanzar aún a los más reticentes.

Las misiones de paz son en estos momentos un nuevo incentivo para la captación de recursos humanos, pues implican una oferta que conjuga, a un tiempo, aventura y solidaridad; en definitiva «un estilo de vida denso y dinámico», como preconizaba hace unos años el Ejército francés en sus folletos de captación de profesionales.

Además de la obtención y gestión de los recursos humanos, las grandes áreas de la Logística son las relativas al abastecimiento a las Tropas de todo cuanto necesitan; el mantenimiento en condición tanto de los combatientes como del material y equipo; el transporte, y, por último, la infraestructura necesaria para estas actividades. De todo ello trataremos a continuación.

\section{El abastecimiento}

$$
\begin{array}{r}
\text { «El punto más vulnerable de cualquier fuerza está ubicado } \\
\text { en el área administrativa, su sistema de abastecimientos, sus bases y } \\
\text { líneas de comunicación. Alli es donde resulta más fácil producirle } \\
\text { un colapso, por ser su lugar más débil. Esta debilidad se hà } \\
\text { incrementado con el progreso técnico». }
\end{array}
$$

Liddel Hart

El abastecimiento de las fuerzas ha constituído siempre el problema fundamental y decisivo para iniciar una campaña y para culminarla con éxito. El abastecimiento abarca a todos los recursos necesarios para las operaciones-víveres, equipo, municiones, vehículos, etc. que deben ser puestos de manera contínua a disposición de las tropas para que éstas puedan satisfacer de forma permanente sus necesidades.

Al ser el abastecimiento consustancial a la misma esencia de la guerra, sus leyes han dictado las de ésta desde el principio de los tiempos. En la Antigüedad, era perentorio llevar la guerra a territorio enemigo para vivir a costa del adversario, y calcular el inicio y la duración de la campaña para que ésta tuviera lugar precisamente cuando ese territorio enemigo tuviera recursos que ofrecer al ocupante. 
Se imponía el movimiento contínuo del ejército, que se podía considerar como un enorme depredador devorando con avidez cuanto encontraba a su paso.

La primera operación de abastecimiento a llevar a cabo es la determinación de los recursos que se precisan, siendo el paso siguiente la obtención de los mismos. Hay una obtención inicial, para satisfacer las necesidades de los primeros momentos de la campaña, y una acumulación de los recursos obtenidos de acuerdo con las previsiones efectuadas. Realizada la acumulación, y una vez iniciadas las operaciones, los recursos deben llegar puntual y contínuamente a sus usuarios, donde quiera que se hallen y en cualquier situación; de lo contrario, el ritmo previsto tendrá que ralentizarse o habrá que detener las fuerzas.

Así pues, los mandatarios de todos los tiempos, y sus generales, han debido tener muy en cuenta todas las operaciones de abastecimiento a la hora de determinar el número y la composición de las tropas; la estructura de las Unidades, los movimientos del ejército y la duración de las campañas. Las experiencias acumuladas a través de los siglos se plasmaron en el nacimiento de Unidades adaptadas no sólo a las circunstancias tácticas sino también a las logísticas, como la Legión romana, el Tercio en la España imperial y la División en la Francia napoleónica.

En 1567 Don Fernando Alvarez de Toledo, Duque de Alba, marchó hacia Flandes con tres Tercios de Infantería de unos 3.000 hombres cada uno y una Caballería compuesta por 1.500 jinetes. Los recursos que ésta relativamente pequeña fuerza transportaba en sus trenes de bagajes y la organización de compras y almacenes que existía a lo largo de su camino, tanto al atravesar territorios del imperio como a través de países aliados, permitieron al ejército del Duque llegar a sus destino y desplegar en él. Una vez asentado en el territorio de los Países Bajos, ricos y capaces de mantener fuerzas de superior entidad, los efectivos imperiales ascendieron a decenas de miles de hombres.

En 1602, durante la campaña de Mauricio de Brabante, se reunieron 3.000 carruajes para acompañar a 24.000 hombres. Ello puede dar una idea de la longitud y extensión de los recursos que las tropas arrastraban con ellas.

En la guerra de los Treinta Años, los ejércitos del rey sueco Gustavo Adolfo y del general imperial Wallenstein llegaron a sumar más de cien mil hombres cada uno. Ello supuso la devastación y el hambre en extensas regiones de Europa Central, obligadas a mantener a sus expensas grandes masas de hombres y ganado que además, y sobre 


\section{El desafío de la logística}

todo en el caso de los suecos, precisaban moverse contínuamente para no perecer de hambre, extendiendo con ello la devastación. Los ejércitos, como gigantescos estómagos, se movían acuciados por su necesidad de subsistir más que por cualquier otra consideración estratégica. Como bestias errantes, recorrían comarcas que necesitaban, tras su paso, un tiempo considerable para recuperarse, por lo que estaban también obligados a no pasar, al menos con determinada frecuencia, por los mismos lugares. Los asedios, que significaban penalidades y sufrimientos para los sitiados, suponían una fuente no menor de problemas para los sitiadores, que esquilmaban la región circundante a la plaza sitiada y, una vez agotados los recursos de aquélla, debían desplazarse cada vez a mayor distancia de su campamento para obtenerlos.

Todas estas consideraciones mantuvieron casi inalterables el ritmo y la duración de las campañas durante mucho tiempo. Podría decirse que, desde Aníbal hasta Napoleón, el problema era fundamentalmente el mismo y la solución que se le daba, por unos y por otros, también. Vivir sobre el terreno, llevando consigo sólo una pequeña parte de lo necesario, devastar las comarcas, requisar y recolectar, y dar por finalizadas las operaciones cuando no se podía mantener el ejército por más tiempo.

Napoleón, sin abandonar ningún principio previo, significó no obstante un cambio sustancial. Sus ejércitos no eran de decenas de miles, sino de centenares de miles de hombres. Había que moverse en orden disperso, para vivir, y acumular las masas para combatir y obtener rápidamente la victoria. La División retomaba el camino de la legión y del tercio. Marchando ordenadamente, por una red viaria mucho más densa que las de la Antigüedad, en la rica Europa, los ejércitos napoleónicos pudieron sostener varias campañas en espacios temporales relativamente cortos. Pero cuando la duración se alargó, o las condiciones del abastecimiento se incrementaron (como en Rusia), la campaña terminó en desastre. $\mathrm{Al}$ parecer, una de las causas de la rápida extensión de las hostilidades contra los franceses a partir del 2 de Mayo fue la rabia acumulada por las contínuas requisas y extorsiones del ejército francés a la población española desde su entrada en España como «aliados».

En ocasiones los estrategas han tendido a subestimar el problema del abastecimiento que, como puede comprenderse, está íntimamente ligado al del transporte, que trataremos más tárde. No es difícil imaginar el agobio de los responsables logísticos ante la magnitud de los problemas que se les presentan: una fuerte centralización logística puede crear numerosos problemas en la parte más baja de la escala -las Pequeñas 
Unidades- y una excesiva descentralización puede generar un amplio desorden y la pérdida o inutilización de numerosos recursos. Frecuentemente, además, no se ha tenido en cuenta que la misma marcha de las operaciones plantea problemas adicionales. En la primera Guerra Mundial, los recursos logísticos no pudieron seguir al Ejército Alemán en Francia; otro tanto ocurrió en la Segunda, cuando Guderian avanzó a mayor ritmo del previsto. Resultado: detenciones forzadas y pérdida del ritmo de avance.

El problema logístico del abastecimiento es, por tanto, extremadamente complejo y difícil, es permanente en su esencia y cambiante con la situación, exige centralizar y descentralizar alternativamente la organización, los medios y el despliegue $y$, desgraciadamente, no siempre o, mejor dicho, casi nunca, le es posible seguir el ritmo de las Unidades más rápidas, por lo que necesita mayores dosis de previsión y cálculo.

Mientras el estratega o el táctico diseñan sus alternativas, el logístico debe estudiar muy profunda y concienzudamente el teatro de operaciones, su estructura económica, la magnitud y naturaleza de sus recursos, sus vías de comunicación, las estructuras urbanas y las características de la población, y la influencia que las operaciones tendrá en todo ello. Deberá a continuación «enlazar» ese teatro con el territorio nacional, sea colindante o no, de forma que la corriente de recursos entre ambos sea fluida y continua, y no sufra cortes totales o parciales que tengan consecuencias graves en la campaña. Tendrá que DETERMINAR, OBTENER, ACUMULAR y MOVER recursos en ambos espacios, el nacional y el del teatro de operaciones, y entre los dos, aprovechando al máximo las comunicaciones y teniendo en cuenta las características de todos los medios posibles de transporte.

Esto le llevará muchas veces a decir «no es posible» al estratega cuando éste proponga sus opciones, y a veces sus observaciones abrirán incluso nuevas perspectivas estratégicas. Un ejército, como un ser vivo, está continuamente consumiendo, y la obligación del logístico es de proporcionarle lo necesario, a mayor ritmo y en mayor volumen si el esfuerzo bélico es mayor, teniendo en cuenta que las mejores previsiones y los cálculos más ajustados pueden venirse abajo en cualquier momento, por lo que debe tener siempre a su disposición un abanico de alternativas.

Hoy día, las características de la guerra y de los materiales han multiplicado las exigencias logísticas y han puesto de manifiesto que ningún país, excepto quizá los Estados Unidos de América, puede enfrentarse por sí solo a los problemas de abastecimiento que su propio 
Ejército plantea. Se impone, pues, unir fuerzas y compartir recursos. No es previsible actualmente un conflicto en el ámbito territorial de la rica y estable Europa del Oeste, por lo que el campo de acción de sus Fuerzas Armadas se ha trasladado, como en el pasado colonial, al exterior de sus fronteras, y el cambio de la misma esencia de la guerra-que ha perdido incluso su nombre en beneficio de otros como tensión, conflicto o crisis- ha propiciado que a la antigua y cruel devastación hayan sucedido otros conceptos, como el de «nación anfitriona», que proporciona recursos no imprescindibles a su población, contribuyendo al esfuerzo bélico y saneando, en algunas ocasiones su economía.

En el conflicto del Golfo, la Arabia Saudita proporcionó puertos, aeropuertos y colaboración a la organización de los movimientos de las fuerzas aliadas, suministró carburante y agua potable, y contribuyó a la alimentación y a proporcionar medios de transporte. De la importancia de esta colaboración da idea el hecho de que, contando con la misma, la División DAGUET, enviada por Francia al teatro de operaciones, recibió del territorio nacional 83.000 toneladas de recursos, 20.000 de ellas de municiones, y que sus Unidades Logísticas distribuyeron 12.000 metros cúbicos de carburante, 250 metros cúbicos diarios de agua y trataron diariamente 20 toneladas de correo.

Un territorio extenso, bien comunicado, que permita desplegar adecuadamente los recursos necesarios en frente y profundidad y - cruzando los dedos - una campaña corta, es lo mejor que puede desear un logístico. Volviendo a la División DAGUET (16.000 hombres y 4.000 vehículos sobre el terreno) la organización específica de los abastecimientos se hizo a partir de las siguientes zonas geográficas de despliegue (CROQUIS $\mathrm{n}^{\circ} 1$ ).

- TOLON: Puerto de embarque en Territorio Nacional.

- YAMBU (excepcionalmente, DAMMAN): Puerto de desembarque.

- RIAD: Base de Transporte Aéreo y escala aérea principal.

- AL ASHA: Base Aérea de Combate.

- CAMPO DEL REY KHALED: Zona de Depósitos Terrestres.

- NORTE DE ARABIA SAUDITA: Zona de Apoyo Logístico Avanzado

- BASE DIVISIOANRIA: Logística Orgánica Divisionaria en la zona de despliegue de la División DAGUET.

Todo ello, con unas distancias logísticas de unos $4.000 \mathrm{Km}$. (7 días de tránsito marítimo) de TOLON a YAMBU, y de $1.600 \mathrm{Km}$ (8 días de tránsito terrestre) de YAMBU a la Zona de despliegue de la División DAGUET y de la Base Aérea de AL ASHA. 
CROQUIS 1

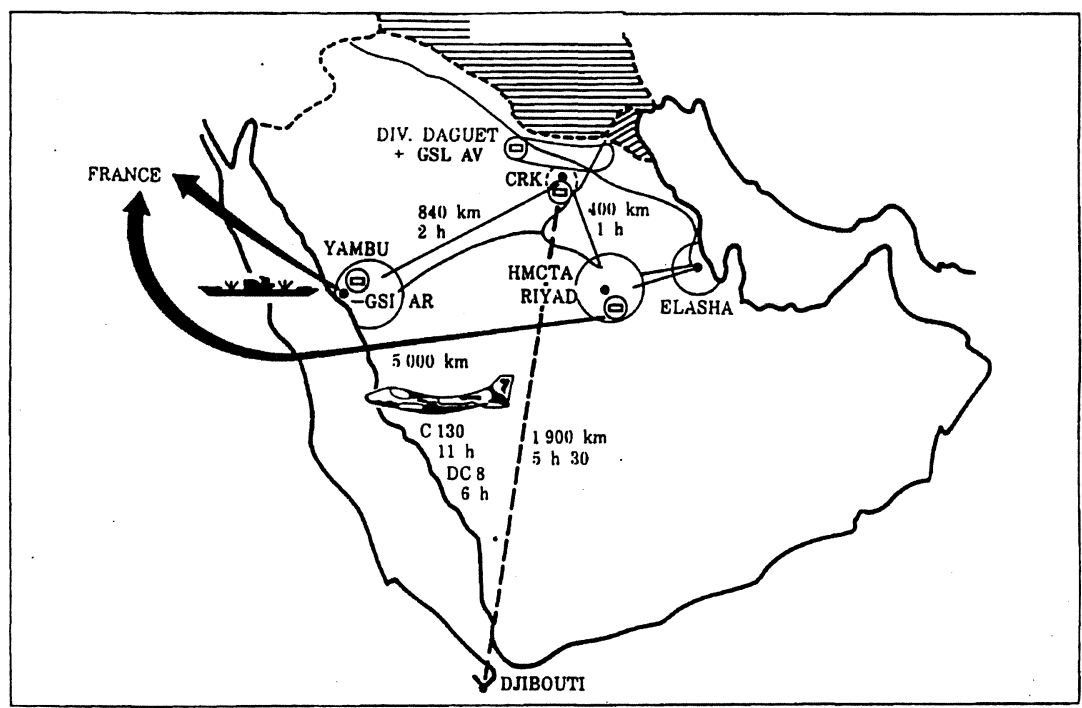

La guerra del Golfo, con los problemas logísticos que planteó, no hizo más que hacer más perentoria la necesidad de realizar cambios estructurales y de abordar cuanto antes la determinación de una «logística de proyección» que fuera capaz de abastecer, en un ambiente multinacional, a fuerzas desplegadas en zonas de conflicto alejadas de la metrópoli.

\section{El mantenimiento}

«El mantenimiento debe ser similar en cantidad y calidad al que disponga el enemigo".

Rommel.

Todo el material, armamento, equipo, medios de transporte, máquinas de Ingenieros, etc. que las tropas precisan para vivir y combatir, debe funcionar continua y adecuadamente, y para ello debe ser mantenido en las mejores condiciones. Sin mantenimiento no hay continuidad, y sin continuidad no hay campaña posible. Una parte importante de los recursos que deben llegar de forma fluida al teatro de operaciones, y a las Unidades, está compuesta de repuestos y piezas de todas clases 


\section{El desafío de la logística}

para mantener en uso el material. Desde las pequeñas Unidades de vanguardia a las grandes Bases Logísticas del interior del Territorio Nacional, la actividad de mantenimiento es incesante, y su importancia, crucial: todo lo que vive o funciona-hombres, animales, carruajes, armas, en otro tiempo; hombres, máquinas, vehículos, armas en la actualidadprecisa de cuidados, con tanta más especialización cuanta más sea su complejidad.

Ni que decir tiene que el problema del mantenimiento ha adquirido en nuestros días proporciones de gran magnitud, que crecen exponencialmente con los avances de la tecnología. Si desde el inicio de la mecanización, las dificultades del mantenimiento del material dispararon el número de quebraderos de cabeza de estrategas y logísticos, en la actualidad su importancia es tan absolutamente crucial que marca la diferencia no ya entre la victoria y la derrota, sino entre la posibilidad y la imposibilidad de la guerra.

En el mundo de intensa relación en que vivimos, la procedencia nacional del material militar no abarca, ni mucho menos, al conjunto del mismo. Solo grandes naciones pueden adoptar una política de Defensa que mantenga la mayor parte de sus fuerzas militares armadas y equipadas con material nacional — caso de Francia- pero ello lleva consigo limitaciones y carencias, sobre todo desde el punto de vista cualitativo, por que nadie es capaz de tener, en todo, lo mejor del mercado; solo una parte del equipo militar que una nación produce tiene como destinatario único a sus Fuerzas Armadas; el resto se exporta. Es el caso de los Estados Unidos, la antigua Unión Soviética, Francia, etc.; la industria de Defensa es un importante pilar de la economía nacional y, al mismo tiempo, un eficaz arma de acción política y diplomática.

Todo ello lleva a la consideración práctica del problema que plantea la procedencia y diversificación del material a mantener. A más diversidad, mayor dificultad, incluso si el material es nacional y, por tanto, relativamente fácil de obtener.

Pongamos un ejemplo: los camiones. Imaginemos que en un determinado Ejército existen cinco tipos: tres de procedencia nacional, y dos de procedencia extranjera. Al cabo de diez años la producción de los cinco tipos de que disponemos ha evolucionado, de forma que los que se producen difiere, en mayor o menor medida, de los que poseemos. ¿Qué hacemos para disponer de piezas de repuesto? ¿Habremos debido adquirir un stock de los modelos antiguos o esperar que, al cabo de diez años, las empresas suministradoras mantengan las mismas piezas? ¿Es mejor comprar una gran masa 
de vehículos cada cierto número de años, con lo que al cabo de los años estarán obsoletos con relación a los que se fabrique en ese momento, o establecer un plan anual de adquisiciones renovando periódicamente el parque?

Este problema, y muchos otros de este tipo, se plantẹan a los logísticos desde hace muchos años. Por definición, un ejército tiende a utilizar el material del vencido si la campaña debe continuar, con lo que economiza o refuerza su propio material. En la Primera Guerra Mundial, y en la Segunda, el Ejército Alemán utilizó vehículos de los países ocupados que pronto comenzaron a plantear problemas de mantenimiento. La diversidad del parque, que al principio proporcionaba las ventajas del número, multiplicaba más tarde los problemas, agravados porque, no conviene olvidarlo, el mantenimiento está ligado no sólo a las instalaciones y herramientas necesarias para el mismo, sino a los especialistas que deben realizarlo.

Como norma general, los tácticos han procurado organizar y mantener al completo las Unidades de combate, dejando "históricamente» las sobras a la Logística. Durante décadas, en toda Europa, la Logística «no se trataba». No es de extrañar que, al comenzar el siglo XX, y pese a las negativas experiencias anteriores, las campañas comenzaran con grandes movimientos estratégicos y tácticos «reales», seguidos de grandes movimientos logísticos «calculados», con lo que a las primeras de cambio comenzaban a descoyuntarse las previsiones realizadas. Si ello es extremadamente grave con el abastecimiento y el transporte, no lo es menos con el mantenimiento, sobre todo cuando no se ha comenzado la campaña con el número de especialistas necesarios. En ambas Guerras Mundiales, hubo que recurrir, de forma creciente, a especialistas civiles para hacer frente en lo posible, a las dificultadeś que surgían. Eso es ahora extremadamente difícil. Por un lado, están las enormes distancias al teatro de operaciones y las condiciones de éste; por el otro, la sofisticación del material actualmente existente, sin olvidar que la militarización de personal civil es un paso grave que sólo circunstancias muy excepcionales en las que esté en juego la supervivencia nacional harían posible.

Diversidad de los materiales y de su procedencia, necesidad de especialistas, instalaciones y herramientas...Como en el caso de los abastecimientos, se impone, por la fuerza de los hechos, la multinacionalidad. Es preciso un detallado despliegue en profundidad de organos de mantenimiento, y un número adecuado de especialistas desde la vanguardia a la retaguardia, un abanico suficientemente amplio y dotado de repuestos, una corriente fluida de éstos hacia delante, y de 


\title{
El desafío de la logística
}

material a reparar hacia atrás. Y, sobre todo, el cuidado de los responsables de las decisiones de adquisición de material en no crear caprichosamente un arsenal militar variopinto, diverso, y, sobre todo, imposible de mantener. De nada sirve poseer el armamento y el material más moderno, si no se es capaz de mantenerlo en perfectas condiciones de empleo, o no se dispone de los especialistas necesarios para repararlo, o no se han adquirido las piezas de repuesto suficientes, o no se ha organizado su distribución rápida y eficaz a los usuarios.

\section{El transporte}

\author{
"Cuanto más conozco la Guerra más me doy cuenta de que \\ todo en ella depende de la administración y del transporte. Poca \\ habilidad o imaginación son precisos para determinar a donde \\ queremos llevar nuestro Ejército y cuándo; hace falta, por el \\ contrario, mucha sabiduría para determinar donde podemos situar \\ nuestras fuerzas, y si podemos mantenerlas alli».
}

General Wavell.

El abastecimiento y el mantenimiento están indisolublemente unidos a los medios y vías que permiten moverse los recursos, es decir a los transportes. La organización del movimiento de los recursos es tan importante como ellos mismos.

En el pasado, recorrían los teatros de operaciones enormes convoyes de carruajes cargados de víveres, municiones, forraje y equipo de todas clases, acompañados de una muchedumbre variopinta que contaba, además de los familiares y sirvientes de los oficiales y soldados, de vendedores, artesanos, cantineras y, en fín, de todos aquellos que de un modo $\mathrm{u}$ otro vivían del ejército. Estas pesadas y largas caravanas, utilizaban para moverse, normalmente, el mismo itinerario de las tropas, a las que seguían sin involucrarse en los combates, pero que, en caso de retirada, podían entorpecer y anular la capacidad de movimiento de aquellas.

Además de estos elementos, que pudiéramos considerar, de algún modo, «orgánicos», las tropas se veían precisadas casi siempre a requisar y utilizar elementos de transporte propios de la población de las zonas que se atravesaban, sobre todo para transportar las ingentes cantidades de forraje que consumía el ganado del ejército, durante siglos el recurso más voluminoso a transportar, ya que el consumo de municiones, tanto 
de Infantería como de Artillería, era relativamente bajo en tiempos de combate a corta distancia y llegada rápida al cuerpo a cuerpo.

Con el tiempo, las necesidades de transporte se acrecentaron al aumentar también-sobre todo a partir de la guerras napoleónicas- el volumen de los ejércitos, y en ellas la preocupación por encontrar y utilizar vías no sólo más númerosas sino también diferentes de aquéllas que utilizaban las tropas.

El ferrocarril vino a satisfacer en gran medida la necesidad de transportar grandes masas de tropa y recursos más rápidamente a gran distancia, pero trajo una dificultad adicional: las vías hacia el frente eran escasas-a veces una vía única- por lo que era preciso transportar hombres y material por el mismo medio y, muchas veces, por el mismo camino, con los tapones, aglomeraciones de organización $y$, en definitiva, desorden resultante. Añádase a ello que la carga y descarga de trenes precisa de suficiente espacio y condiciones en las estaciones y paradas, y que se está siempre sujeto a destrucciones, para hacerse una idea del cúmulo de dificultades que podría amontonarse en las mesas de los responsables del transporte.

Los grandes estrategas europeos siempre fueron conscientes de la importancia de una eficaz organización del transporte no sólo para ganar, sino incluso para mantener vivos a los ejércitos. Cada medio de transporte tiene sus características, es decir, sus ventajas e inconvenientes, por lo que el responsable de los transportes del ejército debe combinar todos ellos de forma que se pueda obtener el máximo rendimiento del conjunto. Una vez más, surge el dilema entre centralización y descentralización, y el arte de combinar ambas. Una excesiva centralización es frecuente causa de mal empleo, pérdida e inoportunidad en el abastecimiento de tropas, material y repuestos, y la excesiva descentralización puede, del mismo modo, desorganizar el sistema, al producirse, con toda probabilidad, un desequilibrio en las prioridades.

La mayor capacidad de transporte de los medios actuales, y la irrupción del transporte aéreo estratégico, ha hecho posible el desplazamiento, en un tiempo relativamente corto, de ingentes efectivos humanos y grandes cantidades de recursos de todas clases a considerables distancias; la Guerra del Golfo fue todo un ejemplo de ello. No hay que olvidar, sin embargo, que nadie hostigó a las fuerzas aliadas ni durante su transporte, ni en su despliegue, ni durante la acumulación, transporte y despliegue de todo lo que necesitaba para operar, que el territorio ocupado era el de un país aliado que abastecía, además, de algo tan esencial como los carburantes y el agua, y que el bando 


\section{El desafío de la logística}

aliado disponía de una superioridad tecnológica abrumadora sobre el adversario, que le permitía una capacidad de gestión muy superior a la de éste.

Hoy por hoy, la escasa capacidad de transporte estratégico es el confesado talón de Aquiles de los países europeos occidentales, siempre necesitados del apoyo norteamericano en este ámbito. La autentica credibilidad militar de la Unión Europea como potencia mundial, dependerá en el futuro del esfuerzo de todos sus países miembros para dotar a sus ejércitos de esta capacidad en grado suficiente para que Europa pueda mover sus Unidades multinacionales allí donde los intereses europeos, que no siempre coincidirán con los norteamericanos, necesiten de su acción.

\section{La infraestructura}

$$
\begin{array}{r}
\text { "...Como quiera que no había puertos de tal magnitud al este } \\
\text { de Bengasi, un ulterior avance estaba abocado a terminar en una } \\
\text { nueva crisis". } \\
\text { Van Cleveld. }
\end{array}
$$

Las Fuerzas Armadas ocupan, de forma permanente, o temporal si están fuera de sus bases habituales, instalaciones más o menos acondicionadas para los hombres y los medios. Cualquier ejército precisa, pues para sus necesidades cotidianas, de una infraestructura específica y adaptada. Las Unidades necesitan bases donde se alojen las tropas, se almacene el material y se mantengan los sistemas de armas y los vehículos. La munición precisa de polvorines para su conservación en condiciones adecuadas, y los continuos ejercicios y maniobras tienen necesidad de campos bien adaptados a las diferentes actividades propias de la milicia. El mantenimiento y la adaptación contínua a las necesidades que plantean los sucesivos cambios en la organización, el despliegue y los medios de los Ejércitos constituye otro campo de acción logística, que precisa, como todas las anteriores, de una buena dosis de previsión y cálculo. Una Base actual tiene poco que ver con los Cuarteles de hace cincuenta años. El ganado ha desaparecido completamente, ocupando su puesto un numeroso y diverso conglomerado de vehículos de todas clases. Las instalaciones de alojamiento, que antes acogían a las Unidades de acuerdo con las condiciones de vida imperante, han debido sufrir sustanciales modificaciones para satisfacer 
las nuevas necesidades individuales de los soldados de hoy, acostumbrados a ciertas comodidades que las antiguas instalaciones no pueden ofrecerles. La Infraestructura, en suma, ha evolucionado al ritmo de las nuevas exigencias sociales, del mismo modo que lo ha hecho la Logística en su conjunto, y esa evolución es permanente, como lo es el contexto social en el que vive, de modo que es una actividad sin fin, que sólo admite detenciones en las épocas de conflicto. Durante muchos años, singularmente durante los largos años de la guerra fría, la infraestructura se pudo considerar funcionalmente una actividad de «tiempos de paz», en el sentido de que, en tiempo de guerra y de suficiente movilización, se habilitaba la infraestructura civil necesaria para acoger a las masas de hombres y medios movilizados y se aprovechaba la existente en territorio enemigo.

Hoy día, la proyección de Unidades a gran distancia del propio territorio plantea los problemas de infraestructura desde otros puntos de vista. En ocasiones, la infraestructura del país anfitrión está devastada. o no existe. La importancia de poseer una «infraestructura móvil», susceptible de ser proyectada con la fuerza, es fundamental, y ello determinará la propia capacidad de proyección. No se trata ya, únicamente, de proyectar un número más o menos grande de tiendas de campaña de barracones prefabricados, sino de estar en condiciones de aportar a las Unidades proyectadas y desplegadas de todo los medios de infraestructura necesarios, desde hospitales más o menos dotados hasta instalaciones de ocio. La gestión de la infraestructura precisa de organizadores y técnicos muy cualificados, y estamos asistiendo al desarrollo de una «infraestructura de proyección» que está llamada a ocupar un papel preponderante en el futuro.

\section{La influencia de las operaciones de paz}

En las postrimerías del siglo que ha contemplado las más grandes batallas de la Historia, han irrumpido con fuerza en ésta las llamadas «operaciones de paz» donde podemos englobar las de mantenimiento y consolidación de la paz, así como las de ayuda humanitaria. En todas ellas se proyectan y despliegan tropas, todas ellas precisan pues, de una organización logística, concebida y prevista desde antes de las crisis para este tipo de operaciones.

La logística de las operaciones de paz guarda sensibles diferencias con respecto a las operaciones militares clásicas: no se puede vivir del país ocupado; al contrario, en la mayoría de la ocasiones, por no 


\section{El desafío de la logística}

decir en todas, hay que ayudar logísticamente a su población. Con frecuencia, el ambiente no es hostil a las Unidades Militares, pero éstas tienen que obrar con exquisita prudencia y objetividad ante la permanente observación de las suspicaces facciones enfrentadas sobre el terreno, que también plantean a veces exigencias logísticas.

En algunos casos, hay que compartir instalaciones con estas facciones, y en otros, controlar incluso la gestión logística de éstas. Todo ello lleva al logístico a tener que lidiar con limitaciones y dificultades añadidas que, en el inicio de la operación, son en muchos casos muy difíciles de prever.Con todo, el problema fundamental de la logística en las operaciones de paz es que, en muchas ocasiones, ha de llevarse a cabo en áreas donde nunca se había previsto antes operar, en escenarios alejados y en circunstancias de ambiente absolutamente desconocidas con anterioridad. La sanidad, el control de las acciones de desminado, el tratamiento y la evacuación de enfermos y heridos, y las labores didácticas en el campo de la logística que hay que realizar no solo en el ámbito de las facciones sino de la población civil constituyen problemas nuevos y específicos a las que hay que enfrentarse con soluciones adaptadas a las circunstancias.

La actuación normal de Unidades de diversos países en este tipo de operaciones crea ventajas e inconvenientes adicionales. La obsesión por la interoperabilidad y por la estandarización en los ejércitos de Occidente es una consecuencia de las necesidades de apoyo de Unidades desplegadas lejos de sus patrias respectivas y en condiciones ambientales difíciles. Sin embargo la logística sigue siendo, en la doctrina multinacional en vigor, un «asunto nacional», por que nadie está de acuerdo en que un Mando de otro país disponga orgánicamente, en territorio extranjero, de los recursos propios.

Existe, eso si, el concepto de «nación lider», que encabeza la alianza o coalición y que en algunos casos es responsable del abastecimiento de determinados recursos al resto, pero en general cada país obtiene y envía la mayor parte de los recursos logísticos que precisan sus tropas. Solo el paso de la «multinacionalidad» a la «supranacionalidad» en la organización común de las fuerzas de países aliados, bastante poco previsible en un futuro inmediato, llevaría consigo la adopción de una logística integrada, que permanecerá hasta entonces como preocupación y responsabilidad de cada uno de los países componentes. Antes, habrá que dar muchos pasos hacia la homogeneidad del armamento y del equipo de los diversos ejércitos, saltando por encima de muchos «tabúes» nacionales y asimilando la integración militar, al menos en el ámbito europeo, con una fuerza no inferior a la ya empleada 
en las integraciones económica y política. Los pasos dados en pos de la fabricación, por ejemplo, del avión de combate europeo, van en esa dirección.

\section{El sistema de apoyo logístico del ejército de tierra español}

Hasta aquí, hemos hecho un rápido repaso de las grandes ramas de la Logística: Abastecimiento, Mantenimiento, Transporte e Infraestructura, que engloban en su seno un cierto número de funciones logísticas. La organización de este mundo complejo ha sido, a través de los tiempos, fuente de preocupación para los diferentes políticos y militares, y ha adoptado diversas modalidades en función de las necesidades sufridas en las diferentes campañas.

Vivimos en una situación que, a nivel mundial, puede considerarse de transición entre dos Eras: la Era Industrial, que agoniza con el milenio, da paso a la Era de la Información, que adquiere cada día mayor solidez e implantación. El mundo de Internet contempla la desaparición del mundo industrial que le precedía, la Sociedad del Saber se extiende a través de las pantallas de los ordenadores, pieza importantísima de la vida normal en millones de hogares. A este mundo integral e informatizado debe acomodarse siquiera sea por puro instinto de supervivencia, la logística. Una logística integrada, asentada su gestión sobre una estructura reticular densísima, de redes informáticas específicas; una logística modular, capaz de satisfacer un amplio abanico de posibles fuerzas a proyectar; una logística adaptada a las posibilidades nacionales; una logística «multinacionalizada» capaz de prestar y acoger, sin grandes traumas, apoyos exteriores. Una logística, en fín, implicada e integrada en el sistema industrial y científico nacional de tal modo que sea capaz de aprovechar todas las ventajas de organización y de gestión de métodos que aquél le brinde.

En la búsqueda de una logística adaptada a los nuevos tiempos, la reciente aprobación -noviembre de 1998- de la Norma de Organización y Funcionamiento del Ejército de Tierra consolidaba la nueva organización de éste de acuerdo con el Plan Norte, lo que suponía también una profunda reestructuración de su organización logística.

Antes de esa fecha se había producido ya un importante cambio conceptual: el paso de una logística de Servicios, fundamentada en los materiales, a una logística de Funciones, basada en las actividades y métodos que pueden realizarse sobre cualquier clase de material, pero con la misma finalidad. Era evidente que los antiguos Servicios 
se quedaban cortos para englobar las tecnologías y sistemas que aparecen continuamente, y que los actuales sistemas de armas están constituídos por equipos y materiales muy diferentes por lo que, en la organización antigua, el mantenimiento de cada uno de los elementos de un solo sistema podía estar encomendado a un Servicio diferente.

Determinadas, pues, las Funciones Logísticas - Personal, Administración, Asistencia Sanitaria, Abastecimiento, Mantenimiento, Transporte, Obras, Asuntos Civiles- había que definir la organización, entendida como un Sistema dentro del Sistema del Ejército de Tierra. De este modo, nació el Sistema de Apoyo Logístico del Ejército que es, por otra parte, el resultado de un proceso de sucesivas reorganizaciones que comenzaron en 1981, con el plan META.

El Sistema de Apoyo Logístico del Ejército (SALE), responde, pues, a criterios de funcionalización, y es el resultado de la dificultad que presentan los complejos sistemas de armas actuales para ser atendidos por un solo Servicio Técnico; de la centralización de la gestión logística, valiéndose para ello de un soporte informático de vital importancia, el Sistema Integrado de Gestión Logística (SIGLE); y de la articulación flexible de los medios, de forma que los recursos no sólo llegen a las Unidades en el momento y lugar oportunos sino que el sistema pueda ser adaptado rápidamente a situaciones de crisis o guerra.

En la nueva estructura, los Mandos del Apoyo a la Fuerza - Mando de Personal y Mando de Apoyo Logístico- se reparten las responsabilidades en lo que respecta a las actividades logísticas. Las funciones de Personal y Asistencia Sanitaria son gestionadas por el Mando de Personal, la de Administración es gestionada por el Estado Mayor del Ejército a través de la Dirección de Asuntos Económicos, y el resto -Abastecimiento, Mantenimiento, Transporte y Obras- por el el Mando de Apoyo Logístico, que se constituye en Escalón Superior del SALE, con cuatro Direcciones encargadas de las grandes áreas de Abastecimiento, Mantenimiento, Transporte e Infraestructura; con un Escalón Intermedio constituído por los Mandos de Apoyo Logístico Regionales y por el Mando de Apoyo Logístico a las Operaciones de la Fuerza de Maniobra, activado, como es el caso actualmente, en las operaciones de proyección exterior y, por último, el Escalón Básico del Sistema está constituido por las Unidades Logísticas y de Servicios, y las de Ingenieros que realizan obras en tiempo de paz.

Este sistema acaba prácticamente de ser puesto en marcha, y ha demostrado su eficacia en su corto período de empleo. Su filosofía es la de adaptar la logística, dentro de las posibilidades de nuestro país, a las exigencias del Ejército español en el siglo XXI, exigencias que 
le demandan, por un lado, el actual contexto internacional y, por otro, una sociedad exigente y abierta, atenta a cuanto ocurre en el mundo y dispuesta a que sus Fuerzas Armadas hagan realidad práctica, en cualquier lugar del planeta, sus ideales de paz, de solidaridad y de colaboración con todos los pueblos. 